\title{
Optimization of the Repeated PWM Command Applied to the Variable Voltage Variable Frequency (VVVF) Converter
}

\author{
Abdelâali Boumaâraf ${ }^{(1)(2)}$ \\ ${ }^{(1)}$ Institute of S T, Abbas \\ Laghrour University Centre, \\ Khenchela, Algeria
}

\author{
Tayeb Mohamadi ${ }^{(2)}$ \\ ${ }^{(2)}$ Department of Electronics, \\ Faculty of technology, Ferhat \\ Abbas University, Setif Algeria
}

\author{
Mohamed Djamel Draou \\ Unité de Recherche en \\ Energie Renouvelable en \\ Milieu Saharien, Adrar, \\ Algeria
}

\begin{abstract}
A new technique of generation signals of the RPWM (repeated pulse width modulation) command have been proposed, by using an alternated and variable repetition of data segments of a reference PWM signal applied. The mathematical aspects and the spectral analysis of this technique are presented as well as the hardware to concretise it. So a optimise concept of this generation will be presented, based independently on the generation of signals command of micro-controller in the aim to reduce the time allocated by this last and to minimise the number of addresses lines between the micro-controller and the memory.
\end{abstract}

\section{General Terms}

Pulse width modulation.

\section{Keywords}

PWM, Asynchronous Motor, Optimization, Converter

\section{INTRODUCTION}

The use of the new commutation circuits based on (MOSFET, IGBT, etc.) allows the increase of the commutation frequency. Consequently, with high switching frequency, current harmonics, motor harmonic losses and pulsating torques will be significantly reduced [1].

The practice of the asynchronous motors pumping systems requires a specific command that takes into account the ration: tension $/$ frequency $=$ constant.

PWM techniques (Pulse Width Modulation) of signal generation command applied in these systems require a great space memory and present limitations of the calculus in the case of the harmonic annulment method [1-16].

The application of data segments repetition technique of a sampled reference signal $[17,18]$, demonstrates some advantages such as: the increase of the commutation number by period, the improvement of the spectrum by the dismissal of the harmonic toward the elevated frequencies, the improvement of the beach of frequency variation, the improvement of the wave of the current and to assure a very optimized command in level of space memory [18].

The application of this last technique showed some inconveniences such as the number of repetition is very high, the high modulation frequency thus the step of increment that becomes bigger to the field of $50 \mathrm{~Hz}$. To remedy these problems, we propose to use an alternated repetition of data segments of a PWM signal.
The advantages considered by this new method are:

- Decrease the increment step (to assure an optimized step of frequency variation).

- Increase the precision of generation of command signals to exploit this technique RPWM in other applications of high precision.

- Improve the loss factor.

- $\quad$ increase the commutation number by period without resorting to a space supplementary memory;

- improve the spectral answer by the dismissal of the harmonic toward the elevated frequencies (multiplication of the harmonic rank);

- $\quad$ assure a large interval of frequency variation $[10 \mathrm{~Hz}-$ $55 \mathrm{~Hz}]$ and a small step frequency change;

- improve the wave of the current (sinusoidal shape without distortion);

- $\quad$ Assure a silence control to the motor level.

\section{Principle of the PWM (Pulse Width Modulation)}

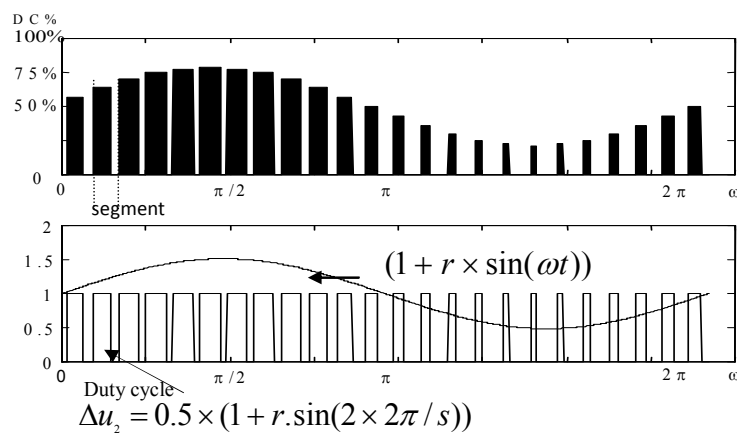

Fig 1. Principle of the PWM control used.

The command signal reference is obtained by sampling the sinusoidal signal. The sampled signal will be therefore constituted of equal length segments. Each segment will be converted in an impulse duty cycle that determines the instantaneous amplitude. Each impulse is converted in a numeric shape of $\mathrm{n}$ bits to represent the closing and opening state of switches related to the three phase power bridge (ton, toff) [18]. In fig. 1 we present the duty cycle percentage of each segment and the command signal wave. 
The tension of phase in the middle point of the bridge (figure 2) is given by:

$$
V u=V d c . \Delta u_{i}
$$

with

$$
\Delta u_{i}=\frac{1}{2} \cdot\left(1+r \cdot \sin \left(\frac{2 \pi \cdot i}{s}\right)\right)
$$

$\Delta \mathrm{u}_{\mathrm{i}}$ : the duty cycle of the ith segment of the $\mathrm{U}$ phase voltage (\% appropriate in opening).

$$
\Delta \mathrm{u}=\text { ton } / \mathrm{Ts}
$$

- Ts: time length of a segment (sampling period).

- $\quad \mathrm{s}$ : number of segment.

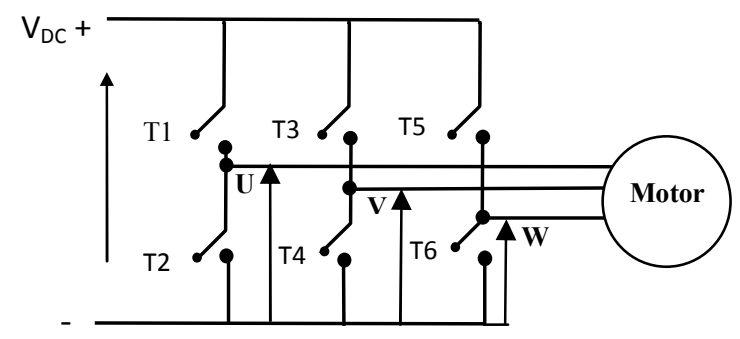

Fig 2. schematic diagram of the converter power unit.

\subsection{Principle of signal frequency variation}

To produce a signal of bass frequency (relatively to the frequency of the reference signal), we produce a sequence of repetitions of each $n$ time segment [18]. The $n$ number is calculated in such a way to get the frequency required by the system. The figure 3 presents, in percentage of the cyclic ratio, command waves where each segment is repeated 2 times, and 3 times.

Technically, the variation of the frequency in the output of the converter will make itself by the number of repetition required for every case, and will make itself by the variation of the frequency of data generation $(f)$. The frequency of the command signal of the motor $(\mathrm{F})$ is calculated by the following formula:

$$
F=\frac{f}{B . S . R}
$$

- $\quad f:$ frequency of data generation.

- $\quad$ B: number of bit.

- $\quad$ S: number of segment.

- $\quad$ R: number of repetition.

The modulation frequency is calculated by the following formula:

$$
F_{m}=\frac{f}{B}=f_{\circ} . S \cdot R
$$

To define the duty cycle of the 6 switches of the inverter power stage, we calculate data for (T1, T3, T5) switches and complement for the opposite switches.
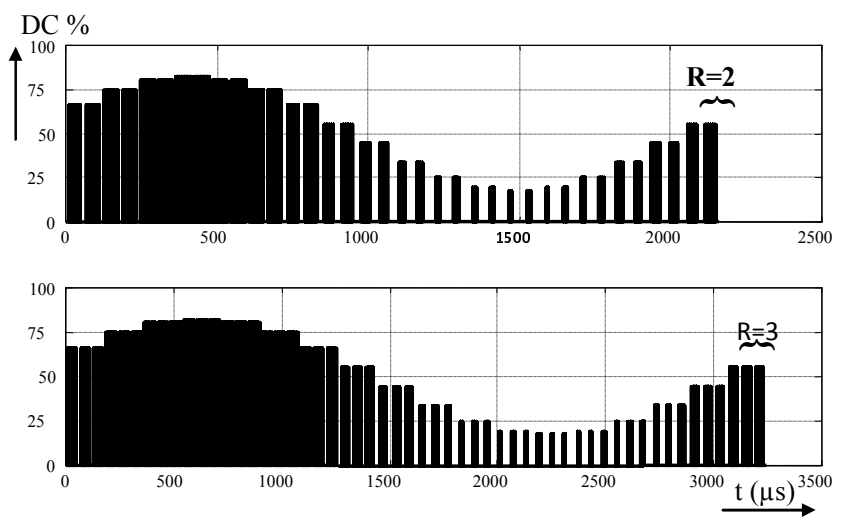

Fig 3. The signal command waves with repetitions

(a) 2 time repetitions

(b) 3 time repetitions

\section{MATHEMATICAL STUDIES}

To really understand the aspect of repetition of the PWM signals and their influence on the spectrum we developed formulas that calculate coefficients of the Fourier series. A program in Matlab calculates the spectral answers that are compared with those of the simulation in order to validate the mathematical formula obtained.

\subsection{Simple repetition of PWM (SRPWM)}

Let's recall the formula calculating the coefficients of Fourier series of the branch tension of a PWM command signal.

$$
\left\{\begin{array}{l}
\mathrm{a}_{\mathrm{n}}=\frac{\mathrm{E}}{\mathrm{n} \pi}\left(1+\sum_{\mathrm{i}=1}^{2 \mathrm{~S}-1}(-1)^{\mathrm{i}} \times \cos \left(\mathrm{n} . \theta_{\mathrm{i}}\right)\right) \\
\mathrm{b}_{\mathrm{n}}=\frac{\mathrm{E}}{\mathrm{n} \pi}\left(\sum_{\mathrm{i}=1}^{2 \mathrm{~S}-1}(-1)^{\mathrm{i}+1} \times \sin \left(\mathrm{n} \cdot \theta_{\mathrm{i}}\right)\right)
\end{array}\right.
$$

where :

- $a_{n}, b_{n}$ : the Fourier coefficient.

- $\mathrm{E}$ : value of the DC tension applied.

- $\theta_{\mathrm{i}}$ : commutation instants.

- $\mathrm{m}$ : number of commutations instant by period

- $\mathrm{n}$ : rank of the harmonic.

- $r$ : number of repetition.

- $\quad \mathrm{s}$ : number of segment. 


$$
\left\{\begin{array}{l}
\theta_{2 \mathrm{p}}=2 \cdot \mathrm{p} \cdot \frac{2 \pi}{S} \\
\theta_{2 \mathrm{p}+1}=\theta_{2 \mathrm{p}}+\frac{\pi}{S}\left(1+\mathrm{r} \times \sin \left((2 \mathrm{p}+1) \cdot \frac{2 \pi}{S}\right)\right)
\end{array}\right.
$$

with $p \in N$

For a segments repetition of this same signal, of $\mathrm{R}$ time with a variable duty cycle, we can calculate the Fourier coefficients by the following formula:

$$
\left\{\begin{array}{l}
a_{n}=\frac{E}{n \cdot \pi}\left(\sum_{i=0}^{2 S-1} \sum_{k=0}^{R-1}(-1)^{i} \cdot \cos \left(n \cdot\left(\frac{k \cdot 2 \cdot \pi}{S \cdot R}+\theta_{i}\right)\right)\right) \\
b_{n}=\frac{E}{n \cdot \pi}\left(\sum_{i=0}^{2 S-1} \sum_{k=0}^{R-1}(-1)^{i+1} \cdot \sin \left(n \cdot\left(\frac{k \cdot 2 \cdot \pi}{S \cdot R}+\theta_{i}\right)\right)\right)
\end{array}\right.
$$

with:

$$
\left\{\begin{aligned}
\theta_{2 \mathrm{p}} & =2 \cdot \mathrm{p} \cdot \frac{2 \pi}{S} \\
\theta_{2 \mathrm{p}+1} & =\theta_{2 \mathrm{p}}+\frac{\pi}{S \cdot R}\left(1+\mathrm{r} \times \sin \left((2 \mathrm{p}+1) \cdot \frac{2 \pi}{S}\right)\right)
\end{aligned}\right.
$$

with $p \in N$

\subsection{Results provided by simulation:}

In figure 2 we present the simulated spectrum of a PWM signal command repeated 2, 3 and 4 times.

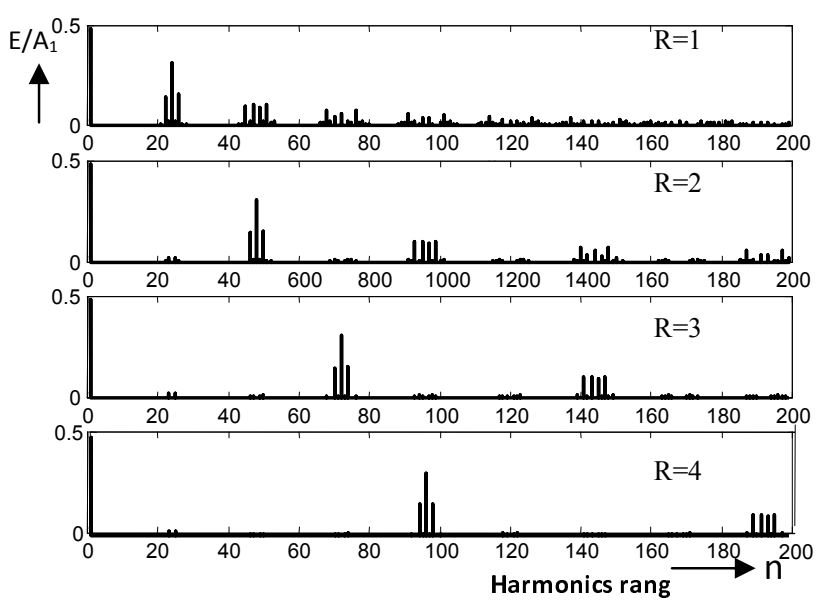

Fig 4. Specter of a simple repeated PWM signal

\subsection{Alternate repetition (ARPWM)}

The problem found in the simple repetition technique (RPWM) is the step frequency variation of the command signal that becomes important in the interval of $50 \mathrm{~Hz}$ (Example we cannot generate a frequency between $48.23 \mathrm{~Hz}$ and $50.08 \mathrm{~Hz}$ [18]). To increase the frequency of data generation witch increases the frequency of modulation and losses by commutations, or to decrease the number of data of segments (Equation $n^{\circ} 4$ ), we suggest a new procedure based on the alternated repetition of data segment, i.e. to repeat segments of the PWM signal alternately; with two different values (for the even and odd segments) as Figure 3 shows.
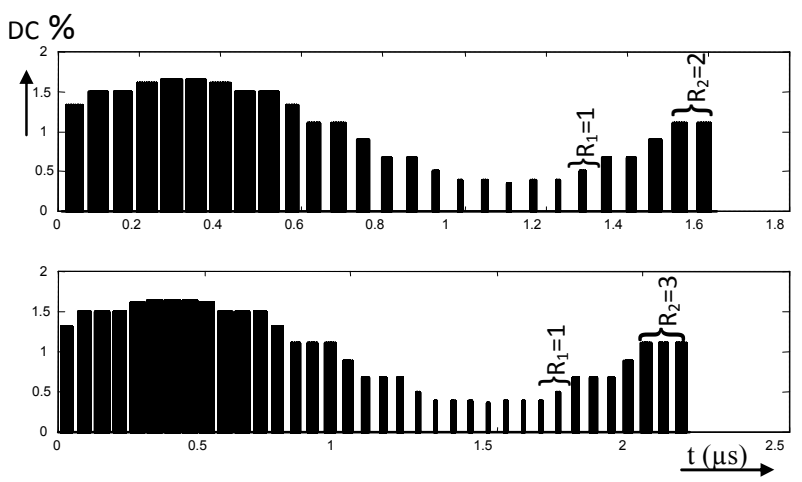

Fig 5. The command signal with repetition

For the R1 and R2 alternated segments repetition, the coefficients of the Fourier series calculate themselves by the following manner: $\mathrm{R}=(\mathrm{R} 1+\mathrm{R} 2) / 2$

$$
\left\{\begin{aligned}
\mathrm{a}_{\mathrm{n}}=\frac{\mathrm{E}}{\mathrm{n} \pi}\left\{\sum _ { \mathrm { i } = 0 } ^ { \mathrm { S } - 1 } \left(\sum_{\mathrm{k}=0}^{R_{1}-1}(-1)^{\mathrm{i}} \cos \left(n \cdot \theta_{i}\right)\right.\right. \\
\left.\left.+\sum_{k=0}^{R_{2}-1}(-1)^{\mathrm{i}} \cos \left(n \cdot\left(\frac{2 \cdot \pi}{\mathrm{S} \cdot \mathrm{R}} \mathrm{R}_{1}+\theta_{i}\right)\right)\right)\right\} \\
\mathrm{b}_{\mathrm{n}}=\frac{\mathrm{E}}{\mathrm{n} \pi}\left\{\sum _ { \mathrm { i } = 0 } ^ { \mathrm { S } - 1 } \left(\sum_{\mathrm{k}=0}^{R_{1}-1}(-1)^{\mathrm{i}+1} \sin \left(n \cdot \theta_{i}\right)\right.\right. \\
\left.\left.+\sum_{k=0}^{R_{2}-1}(-1)^{\mathrm{i}+1} \sin \left(n \cdot\left(\frac{2 \cdot \pi}{\mathrm{S} \cdot \mathrm{R}} \mathrm{R}_{1}+\theta_{i}\right)\right)\right)\right\}
\end{aligned}\right.
$$

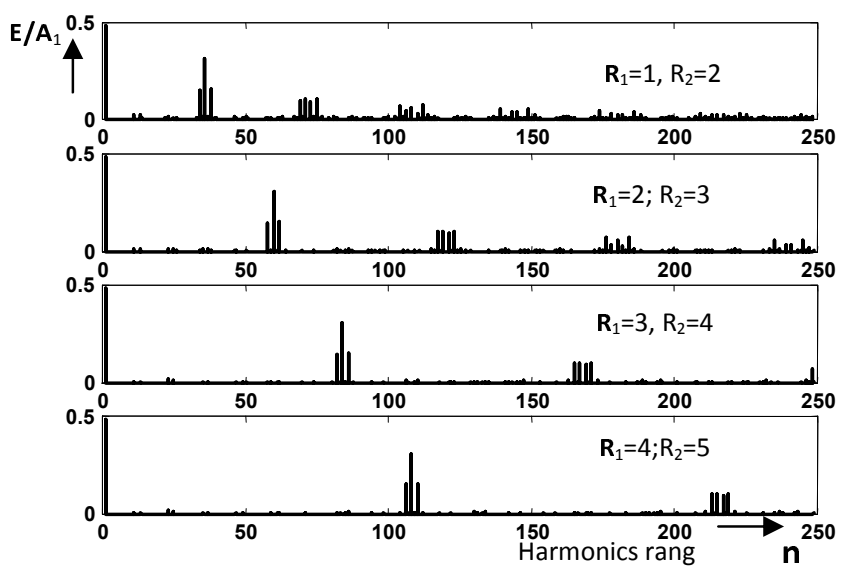

Fig 6. Specter of a repeated alternated signal

We notice that the application of the alternate repetition produces a light influence on the spectrum, relatively to the simple repetition, with the appearance of the multiple rank of the 
segment numbers divided by two of the under-carrier. But regard to the negligible value of their amplitude, and due to the presented advantages, we can consider this procedure as a new method of generation of the PWM signals for use in applications with high precision.

\subsection{Loss factors}

The loss factor is one of the main performance indices of the PWM strategy command whose optimal solution is obtained with the minimization of this quantity. The definition is given as follows:

$$
\sigma=\sqrt{\sum_{n=2}^{Q}\left(\frac{V_{n}}{n}\right)^{2}}
$$

$\mathrm{Q}=10 \mathrm{xN}, \mathrm{N}$ : number of commutations by $1 / 4$ of period [6].

In our case: $Q=5 x S x R$.

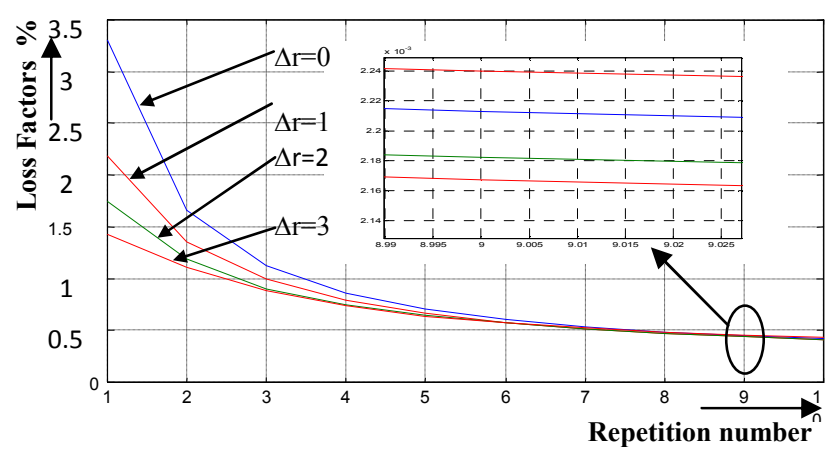

Fig 7. Loss factors comparison between $\Delta \mathbf{r}$ according to repetition number.

We notice in fig. 5, that the rate of loss factor decreases when the number of repetition increases and also this factor improves with the increase of the difference between values of the two repetitions of the even and odd segments $(\Delta \mathrm{r})$. To optimize the command of the PWM modulation with alternate repetition we make a compromise between the value of the loss factor and the value of the amplitude of the appearing harmonics.

\subsection{Variable Repetition}

We present in this part the development series Fourier for a general case Fig.7. Each segment $i$ is repeated with a different value $R_{i}$ of other segments in order to improve the pace of change in frequency and accuracy in the generation of signals:

$$
\left\{\begin{array}{c}
a_{n}=\frac{E}{n \pi}\left(1+\sum_{i=1}^{2 . s-1} \sum_{k=1}^{R_{i}-1}(-1)^{i} \cdot \cos \left(n \cdot \theta_{i}\right)\right) \\
b_{n}=\frac{E}{n \pi}\left(\sum_{i=1}^{2 . s-1} \sum_{k=0}^{R_{i}-1}(-1)^{i+1} \cdot \sin \left(n \cdot \theta_{i}\right)\right)
\end{array}\right.
$$

with:

$$
\left\{\begin{array}{l}
\theta_{2 p}=\frac{2 . \pi}{\mathrm{S} . \mathrm{R}}\left(\sum_{\mathrm{j}=0}^{\mathrm{i}} \mathrm{R}_{\mathrm{j}}+\mathrm{k}\right) \\
\theta_{2 p+1}=\theta_{2 p}+\frac{\pi}{\mathrm{S} . \mathrm{R}}\left(1+\mathrm{r} \cdot \sin \left(\frac{2 \pi}{\mathrm{S}} \mathrm{i}\right)\right)
\end{array}\right.
$$
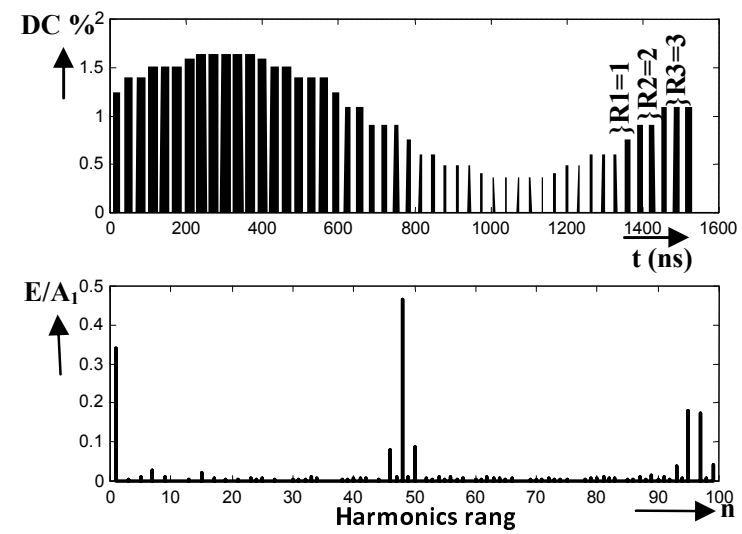

Fig 8. Shape and Spectrum of a variably repeated PWM control signal $(R 1=1, R 2=2, R 3=3)$

So the frequency signal generated is calculated as follows:

$$
F=\frac{f}{b \times \sum_{i=1}^{S} R_{i}}
$$

To demonstrate the utility of this procedure, we present a repeat of two segments of the reference signal, having a symmetry to obtain a signal of reduced frequency and duty cycle to maintain constant sinusoidal signal.
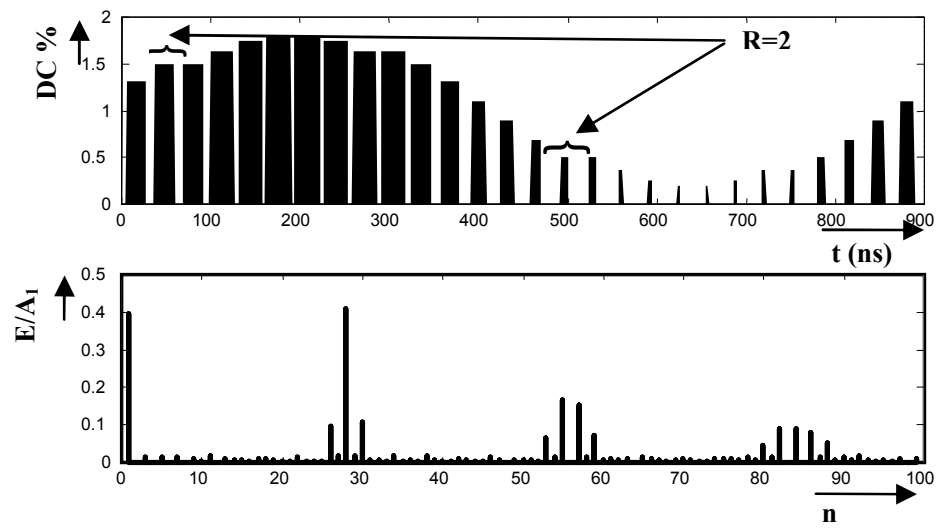

Fig 9. Shape and spectrum of a variable repeated PWM control signal, step $\min (\mathrm{R} 2=2, \mathrm{R} 13=2)$

\section{Comparative study}

The comparative study is devoted to no change in frequency for the three developed techniques, although we notice that this step improves with increased number of repetitions and it is better for technical VRPWM. In Table No. 1 we present the formulas calculating the minimum variations in the frequency $(\Delta F)$ that can be obtained between two signals generated $\left(F_{1}\right.$ and $\left.F_{2}\right)$ for the three cases studied. 
Table 1 : Minimal frequency variation

\begin{tabular}{|c|c|c|c|}
\hline & SRPWM & ARPWM & VRPWM \\
\hline$F_{1}$ & $\frac{f}{b \cdot S \cdot R}$ & $\frac{f}{b \cdot S \cdot R}$ & $\frac{f}{b \cdot S \cdot R}$ \\
\hline$F_{2}$ & $\frac{f}{b \cdot S \cdot(R+1)}$ & $\frac{2 \cdot f}{b \cdot S \cdot(2 \cdot R+1)}$ & $\frac{f}{b \cdot(S \cdot R+2)}$ \\
\hline$\Delta F$ & $\frac{f}{b . S . R .(R+1)}$ & $\frac{f}{b \cdot S \cdot R \cdot(2 R+1)}$ & $\frac{2 \cdot f}{b \cdot S \cdot R \cdot(S \cdot R+2)}$ \\
\hline
\end{tabular}

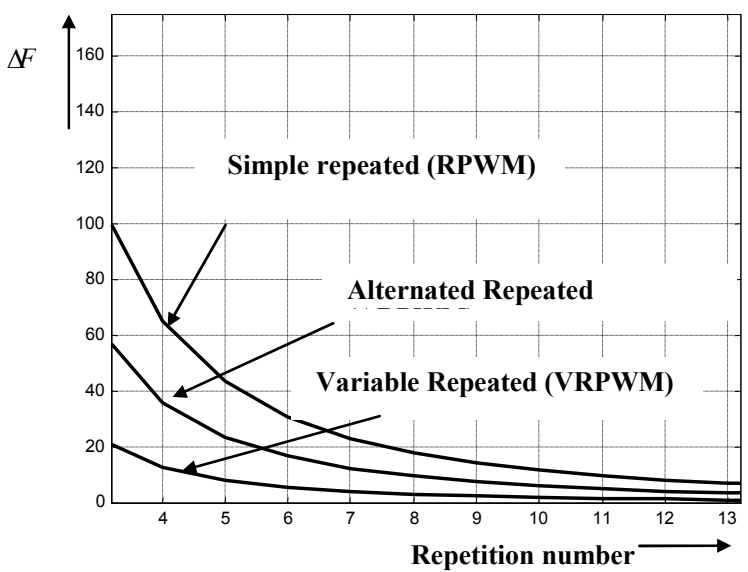

Fig 10. Variation frequency of VRPWM according to repetition number.

\section{ELECTRONIC COMMAND CIRCUIT}

The electronic command circuit is conceived to concretize the theoretical survey and to generate a PWM command signals with simple and alternate repetition (RPWM and ARPWM). This technique requires a generation of command signals independently with a very high frequency in the order of $1 \mathrm{MHz}$, to sweep an acceptable field frequency. In this case, the signal generation of the micro-controller become unavoidable. Therefore, we opted for a sequential addressing system independently of the micro-controller that can assure the sweep of predefined data, stocked in the EPROM under numeric shape, with autonomous repetition without the intervention of the micro-controller. This last has measuring, testing, numbering and assuring the command signals to go from a segment to other also the increments and decrements of depths.

This concept has for advantage to assure the generation of short length signals, the reduction of address lines between the microcontroller and the data memory and the reduction of the time allocated by the micro-controller. Therefore amore effective systems (DSP, FPGA,...) for the generation of this command type, is useless.

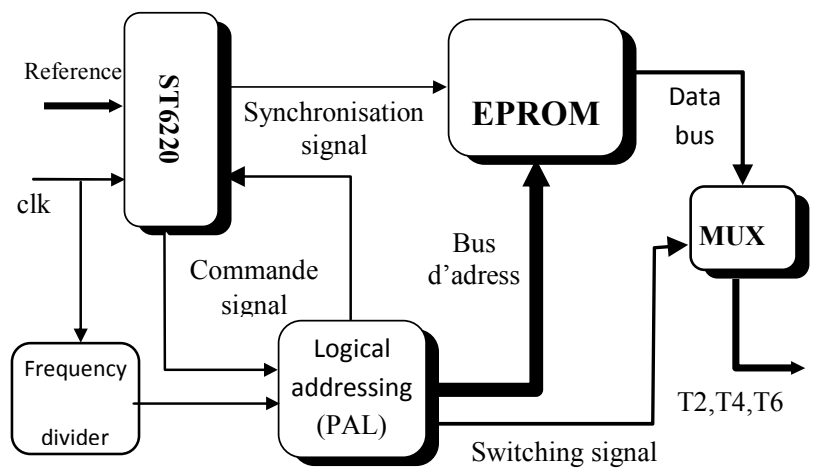

Fig 11. The diagram of command circuit

\section{Applications of survey results}

In table 2, we give some values of frequency that we have calculated and used in tests of converter, as well as the number of repetition for the two segments, the gain in memory obtained by our structure and steps of frequency variation for the three cases (simple, alternate and variable repetition). We notice that the new suggested technique VRPWM allows us to reach the intermediate frequencies without the change of the modulation frequency that remains $31.26 \mathrm{kHz}$ [4] with a step of variation decreased to $0.2 \mathrm{~Hz}$ in the interval of $50 \mathrm{~Hz}$ and $0.0075 \mathrm{~Hz}$ in the interval of $10 \mathrm{~Hz}$.

Table 2 : Memory gain and variation frequency of etch method of signal generation

\begin{tabular}{|c|c|c|c|c|c|c|c|c|c|}
\hline $\begin{array}{c}\text { Frequency } \\
(\mathrm{Hz})\end{array}$ & $\begin{array}{c}\text { Number of } \\
\text { pair segments } \\
\text { repetitions }\end{array}$ & $\begin{array}{l}\text { Number of } \\
\text { impair } \\
\text { segments } \\
\text { repetitions }\end{array}$ & $\begin{array}{l}\text { Number of } \\
\text { (R2 et R14) } \\
\text { repetitions }\end{array}$ & $\begin{array}{c}\text { Generated } \\
\text { data } \\
\text { (octet) }\end{array}$ & $\begin{array}{c}\text { Stockade } \\
\text { data } \\
\text { (octet) }\end{array}$ & $\begin{array}{l}\text { memory } \\
\text { Gain }\end{array}$ & $\begin{array}{c}\text { variation } \\
\text { frequency of } \\
\text { RPWM }(\mathrm{Hz})\end{array}$ & $\begin{array}{c}\text { Variation } \\
\text { frequency of } \\
\text { ARPWM } \\
(\mathrm{Hz})\end{array}$ & $\begin{array}{c}\text { Variation } \\
\text { frequency of } \\
\text { VRPWM } \\
(\mathrm{Hz})\end{array}$ \\
\hline 59,1856 & 22 & 22 & 22 & 16896 & 768 & 22,00 & ----- & ---- & $*$ \\
\hline 58,9623 & 22 & 22 & 23 & 16960 & 768 & 22,08 & $*$ & $*$ & 0,2233 \\
\hline 58,7406 & 22 & 22 & 24 & 17024 & 768 & 22,17 & $*$ & $*$ & 0,2217 \\
\hline 58,5206 & 22 & 22 & 25 & 17088 & 768 & 22,25 & $*$ & $*$ & 0,2200 \\
\hline 58,3022 & 22 & 22 & 26 & 17152 & 768 & 22,33 & $*$ & $*$ & 0,2184 \\
\hline 58,0855 & 22 & 22 & 27 & 17216 & 768 & 22,42 & $*$ & $*$ & 0,2167 \\
\hline 57,8704 & 22 & 22 & 28 & 17280 & 768 & 22,50 & $*$ & $*$ & 0,2151 \\
\hline 57,8704 & 23 & 22 & $* *$ & 17280 & 768 & 22,50 & $*$ & 1,3152 & $*$ \\
\hline 57,6568 & 22 & 22 & 29 & 17344 & 768 & 22,58 & $*$ & $*$ & 0,2135 \\
\hline 57,4449 & 22 & 22 & 30 & 17408 & 768 & 22,67 & $*$ & $*$ & 0,2120 \\
\hline 57,2344 & 22 & 22 & 31 & 17472 & 768 & 22,75 & $*$ & $*$ & 0,2104 \\
\hline
\end{tabular}




\begin{tabular}{|c|c|c|c|c|c|c|c|c|c|}
\hline 57,0255 & 22 & 22 & 32 & 17536 & 768 & 22,83 & * & * & 0,2089 \\
\hline 56,8182 & 22 & 22 & 33 & 17600 & 768 & 22,92 & $*$ & * & 0,2074 \\
\hline 56,6123 & 22 & 22 & 34 & 17664 & 768 & 23,00 & * & * & 0,2059 \\
\hline 56,6123 & 23 & 23 & $* *$ & 17664 & 768 & 23,00 & 2,573 & 1,2581 & $*$ \\
\hline 56,4079 & 23 & 23 & 24 & 17728 & 768 & 23,08 & $*$ & $*$ & 0,2044 \\
\hline 56,2050 & 23 & 23 & 25 & 17792 & 768 & 23,17 & $*$ & $*$ & 0,2029 \\
\hline 56,0036 & 23 & 23 & 26 & 17856 & 768 & 23,25 & $*$ & $*$ & 0,2015 \\
\hline 55,8036 & 23 & 23 & 27 & 17920 & 768 & 23,33 & * & $*$ & 0,2000 \\
\hline 55,6050 & 23 & 23 & 28 & 17984 & 768 & 23,42 & * & $*$ & 0,1986 \\
\hline 55,4078 & 23 & 23 & 29 & 18048 & 768 & 23,50 & $*$ & $*$ & 0,1972 \\
\hline$\ldots$. & $\ldots \ldots$ & $\ldots$. & $\ldots$. & $\ldots$. & $\ldots \ldots$ & $\ldots \ldots$ & $\ldots \ldots$ & $\ldots \ldots$ & $\ldots$ \\
\hline 10,8507 & 120 & 120 & $* *$ & 92160 & 768 & 120,00 & ---- & ----- & $*$ \\
\hline 10,8432 & 120 & 120 & 121 & 92224 & 768 & 120,08 & $*$ & $*$ & 0,0075 \\
\hline 10,8356 & 120 & 120 & 122 & 92288 & 768 & 120,17 & $*$ & * & 0,0075 \\
\hline 10,8281 & 120 & 120 & 123 & 92352 & 768 & 120,25 & $*$ & * & 0,0075 \\
\hline 10,8206 & 120 & 120 & 124 & 92416 & 768 & 120,33 & $*$ & $*$ & 0,0075 \\
\hline
\end{tabular}

\section{TEST AND MEASURES}

The test and measurements of the process command achieved as well as the whole converter permitted us to raise very satisfactory results as tensions and the currents of lines $(\mathrm{Vu}$ $\mathrm{Vw}$ ) as well as their specters gotten by FLUK 41B, that is represented on the Fig. 6, gotten with a motor of $1 \mathrm{kw}$ and a tension $\mathrm{Vdc}=300 \mathrm{v}$ for two frequency $10.3 \mathrm{~Hz}$ and $49 \mathrm{~Hz}$. The used parameters are a number of segment $S=24$, the number of bits $\mathrm{B}=32$. We notices good that the spectral answer and very improved relatively to the other application.
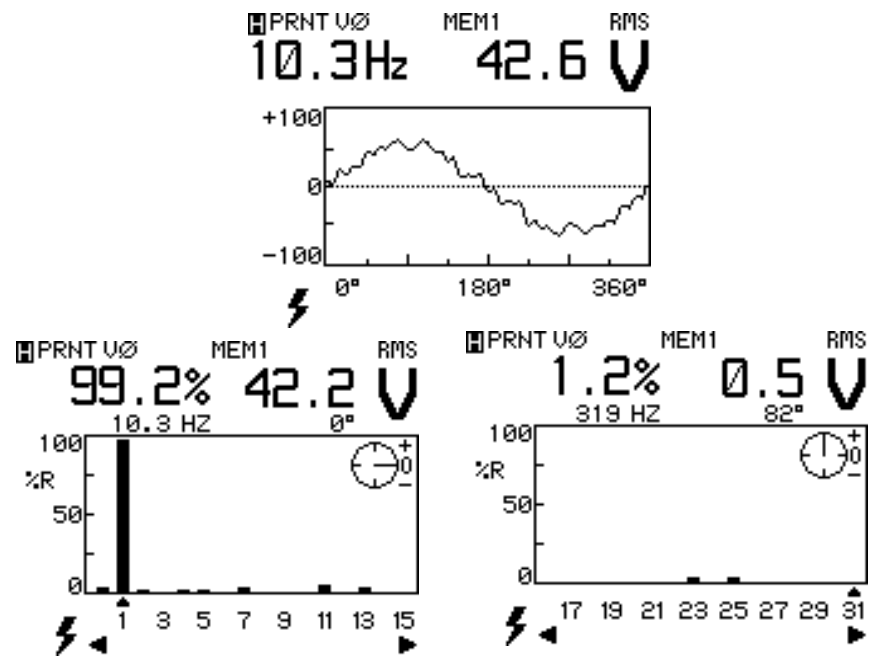

Fig 12. Practice results tension with the 31 st harmonics analyses $f=10.3 \mathrm{hz}$
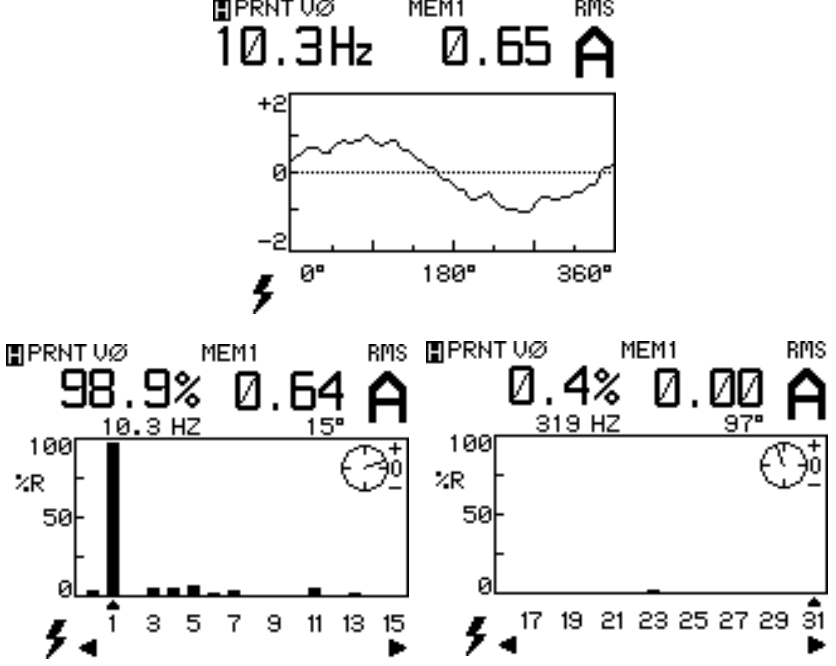

Fig 13. Practice results courant with the 31 st harmonics analyses $f=10.3 \mathrm{~Hz}$
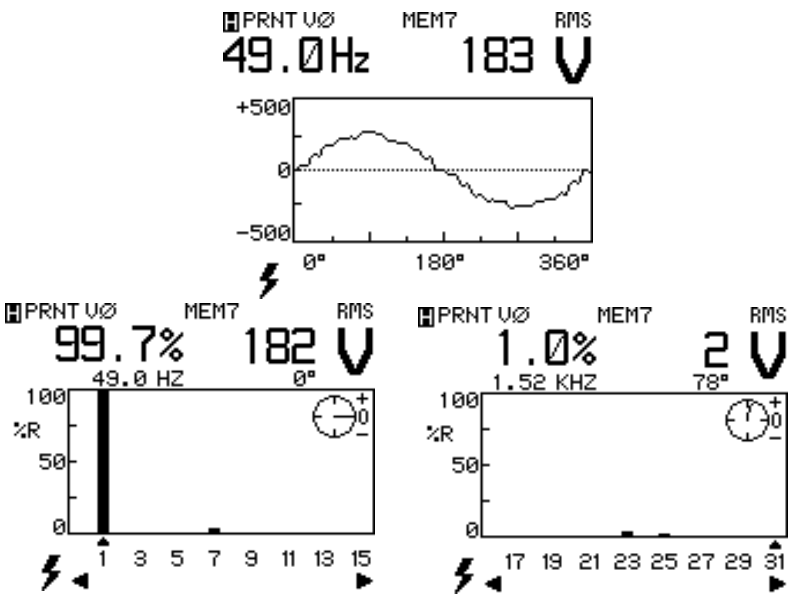
Fig 14. Practice results tension with the 31st harmonics analyses $\mathrm{f}=49 \mathrm{~Hz}$

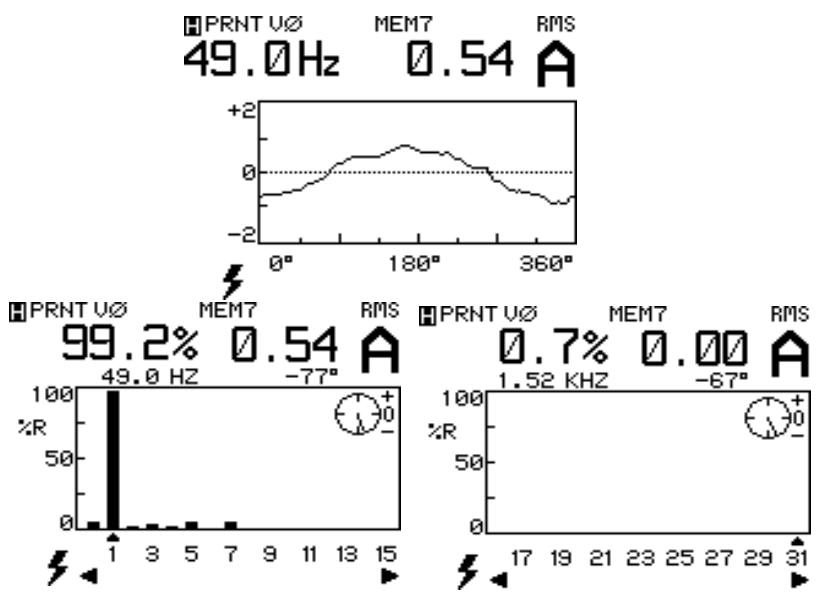

Fig 15. Practice results courant with the 31 st harmonics analyses $\mathrm{f}=49 \mathrm{~Hz}$

\section{CONCLUSION}

In this work, a survey of the PWM command with simple, alternate and variable repetition has been proposed, concretized by an optimized hardware in the choice of components, gain in memory that can reach 120 times, the gain in time reserved by the micro-controller that can attain 50\%, The harmonic frequencies are pushed to higher frequencies and the sensitivity of the signal generation that is one micro-second. Also, the new technique proposed VRPWM has improved the step of frequency variation especially in the interval of $50 \mathrm{~Hz}$ which reduced to $0.0075 \mathrm{~Hz}$.

\section{REFERENCE}

[1] Y.Tadors, S. Salama, Th. Schütze; "Three Level IGBT Inverters for Industrial Drives and Traction Applications" EPE Journal; vol.4 n²; (June 1994), pp.38-42;.

[2] Y. Aït Gougam, A. Nafa, T. Morsli, "Étude des techniques de modulation optimale pour onduleur de tension alimentant un moteur asynchrone". 2nd CEA Algiers, Vol.1, (Nov.1994), pp.11-17.

[3] M. D. Draou, S. A. Chikhi, "Three-phase inverter for photovoltaic pumping managed with $\mu$ p6802", Proc. of World Renewable Energy Congress VI (WREC2000), pp 2085-2088.

[4] H. Bülent Ertan, N. Balkan Simsir, "Comparison of PWM and PFM Induction Drives Regarding Audible Noise and Vibration for Household Applications", IEEE transactions on industry applications, VOL. 40, NO. 6, (Nov/Dec 2004), PP 1621-1628.

[5] H. Kanaan, K. Al-Haddad, R. Chaffaï, L. Duguay and F. Fnaiech, "A comparative study of hysteresis and PWM control techniques applied to an injection-current-based three-phase rectifier", CCECE 2001 Conference, Toronto, Ontario, (May 14-16, 2001), pp 785-792.

[6] Hyo L. Liu, Gyu H. Cho, Sun S. Park, "Optimal PWM Design High Power Three-Level Inverter Through Comparative Studies", IEEE Tran. On Power Elec., vol.10, $\mathrm{N}^{\circ} .1$, (Jan.1995), pp 38-47.
[7] Ruhe Shi Hamid, A. Toliyat, "Vector Control of Five-Phase Synchronous Reluctance Motor with Space Vector Pulse Width Modulation (SVPWM) for Minimum Switching Losses", IEEE International on Industrial Technology, (2008), pp 57-63.

[8] K. K. Tse, Henry Shu-Hung Chung S. Y. Ron Hui H. C. So "Comparative Study of Carrier-Frequency Modulation Techniques for Conducted EMI Suppression in PWM Converters" IEEE transactions on industrial electronics, VOL. 49, NO. 3, (JUNE 2002), PP 618-627.

[9] R. Bojoi, A. Tenconi, F. Profumo, G. Griva, D. Martinello, "Complete Analysis and Comparative Study of Digital Modulation Techniques for Dual Three-phase AC Motor", IEEE Power Electronics,(2002), pp 851-857

[10] John N. Chiasson, Leon M. Tolbert, Keith J. McKenzie and Zhong Du, Student Member, "A Complete Solution to the Harmonic Elimination Problem", IEEE transactions on power electronics, VOL. 19, NO. 2, (MARCH 2004), pp 491-499.

[11] Daniel John Tooth, Neville McNeill, Stephen J. Finney, Barry W. Williams,"A New Soft-Switching Technique Using a Modified PWM Scheme Requiring No Extra Hardware", IEEE transactions on power electronics, VOL. 16, NO. 5, (Sep 2001), pp 686-693.

[12] Byoung-Kuk Lee, Student, Mehrdad Ehsani, "A Simplified Functional Simulation Model for Three-Phase VoltageSource Inverter Using Switching Function Concept", IEEE transactions on industrial electronics, VOL. 48, NO. 2, (Apr 2001), PP 309-321.

[13] Shui-Sheng Qiu and I. M. Filanovsky, "Harmonic Analysis of PWM Converters" IEEE transactions on circuits and systems - i: fundamental theory and applications, VOL. 47, NO. 9, (Sep 2000), PP 1340-1349.

[14] Sidney R. Bowes, Sukhminder Singh Grewal, "Novel Space-Vector-Based Harmonic Elimination Inverter Control", IEEE transactions on industrial applications, VOL. 36, NO. 2, (Mar/Apr 2000), pp 549-557.

[15] Rup Narayan Ray, Debashis Chatterjee, Swapan Kumar Goswami, "An application of PSO technique for harmonic elimination in a PWM inverter", Volume 9, Issue 4, (Sep 2009), Pages 1315-1320.

[16] Pairoj piyarungsan, Somyot kaitwanidvilai, "Harmonic Reduction Technique in PWM AC Voltage Controller using Particle Swarm Optimization and Artificial Neural Network", Proceedings of the International Multi Conference of Engineers and Computer Scientists 2010 Vol II, (2010).

[17] B. Maurice, JM. Bourgeois \& B.Saby, "Versatile cost effective induction motor drive with tree phase digital generation", (PCIM 1991), Nürnberg.

[18] A. BOUMAARAF, M.D. DRAOU, S.CHIKHI, "Nouveau concept de la commande PWM destiné au système de pompage photovoltaïque", Revue des énergies renouvelables, vol. 5, no2, (2002), pp. 139-147. 